\title{
The Case for Inflation Stability *
}

\author{
Fabrice Collard ${ }^{a}$ Harris Dellas ${ }^{\mathrm{b}, 1}$ \\ ${ }^{\mathrm{a}}$ CNRS-GREMAQ, IDEI, University of Toulouse, 31000 Toulouse, France \\ ${ }^{\mathrm{b}}$ Department of Economics, University of Bern, CEPR and IMOП, 3012 Bern, \\ Switzerland
}

\begin{abstract}
We evaluate the case for inflation stabilization in a New Keynesian (NNS) model that includes various frictions, capital accumulation and a variety of shocks. In such a model, price rigidity may provide the monetary authorities with an opportunity to improve upon the inefficient flexible price equilibrium via the suitable cyclical manipulation of real marginal costs. We find that such an opportunity is of limited value and that a strong case for perfect inflation stabilization remains. Policies that tolerate a small amount of inflation variability may outperform perfect inflation targeting when capital adjustment costs are low and the monetary distortion is substantial but only if prices are very flexible.
\end{abstract}

Key words: Inflation stabilization, investment, price rigidity, distortions JEL Classification: E32 E52

\section{Introduction}

The recent literature on optimal monetary policy has studied extensively the welfare properties of price (or inflation) targeting within the New Neoclassical

\footnotetext{
^ We are grateful to Bob King for numerous valuable suggestions. We would also like to thank Patrick Minford and seminar participants at the Konstanz seminar, CRETE, the SCE-SED 2004 Amsterdam meetings, and the Catholic University of Leuven for constructive comments.

1 Corresponding Author: Harris Dellas, VWI, Gesellschaftsstrasse 49, CH 3012 Bern, Switzerland; Tel: (+41) 31-631-3989, Fax: (+41) 31-631-3992; E-mail: harris.dellas@vwi.unibe.ch; url: http://www-vwi.unibe.ch/amakro/dellas.htm
} 
Synthesis, NNS (or, new Keynesian, NK) model. This literature has established that in the absence of capital accumulation and money demand frictions, a policy of price stability is approximately optimal (Clarida, Galí and Gertler (1999), Goodfriend and King (1997), Woodford (2003)).

Money demand frictions have well known implications for the properties of optimal monetary policy. In addition to the standard Friedman zero nominal interest rate rule, their presence also induces a bias in favor of interest rate stabilization. Combined with rigid prices, they create a genuine tension between eliminating the relative price and the money demand distortion. Nonetheless, Khan, King and Wolman (2003) and Woodford (2003) show that, under some restrictions on preferences, production and the type of shocks, this tension is resolved overwhelmingly in favor of addressing the first distortion so that optimal deviations from price stability are likely to be small.

The implications of the presence of capital accumulation for the properties of optimal policy have received less attention and have also proved harder to assess. Observing that the markup acts as a tax on inputs and relying on optimal taxation principles, Goodfriend and King (2001) speculate that price stability would remain optimal in the NNS model even when capital were included 2 Nonetheless, this conjecture has not yet been formally addressed.

Our objective is to examine the case for perfect inflation stabilization in a more realistic model that includes capital accumulation, shocks to technology, government expenditures and the demand for money and where the flexible price equilibrium is inefficient due to an imperfect competition distortion and a monetary friction. Most of the literature deals with price targeting and does not distinguish too carefully between that and inflation targeting. We have opted for studying the latter as it seems more relevant for economies which, like their real world counterparts, exhibit sustained nominal growth. Moreover, abstracting from the money demand friction, our formulation allows for long term money neutrality, a desirable feature in the analysis of monetary policy.

\footnotetext{
$\overline{2}$ Note, though, that there exists an important difference between the standard tax smoothing argument and that of markup constancy. In the former, both the average tax rate and its variation are optimally selected. In the latter, the steady state tax rate (markup) is exogenous and only its cyclical variation is selected.
} 
We solve the model using a second order approximation to the policy functions in order to compute accurate welfare measures (see Woodford (2003)). We do not attempt to characterize the globally optimal policy (a computationally demanding strategy) but instead restrict ourselves to a simpler but quite valuable task. Namely, to the investigation of whether commonly studied policies that entail substantial price variability, such as a Henderson-McKibbin-Taylor (see Henderson and McKibbin (1993)) rule with imperfect inflation targeting or money or interest rate targeting, outperform perfect inflation stabilization. Admittedly, such an approach has the weakness that the rules considered may not be close to the globally optimal rule. And that the parameters of the rule are taken for granted rather than chosen to optimize outcomes within these rules. Nonetheless, it still seems interesting to study this issue as we think that it is important to evaluate whether simple rules that have been the subject of much recent discussion among academics and central bank economists can produce welfare that is not too different from the heralded constant inflation (or perfect price stability) rule.

We search across a large set of model specifications, involving variation in several key features (the degree of risk aversion, capital adjustment costs, the degree of nominal rigidity, the size of the average mark up, and the size of money demand frictions). Our results can be summarized as follows. In the vast majority of cases, perfect inflation targeting dominates the simple rules considered.

In a few cases, perfect inflation targeting is outperformed by some of these rules. But this occurs only when prices are very flexible which implies a minor role for monetary policy.

Consequently, while the presence of capital accumulation and a monetary friction may undermine qualitatively the case for perfect inflation stability, this occurs in situations of little practical interest and is of negligible quantitative importance.

The remaining of the paper is organized as follows. Section 1 presents the model economy. Section 2 discusses parameter selection. The main findings are presented in section 3 . 


\section{The model}

The setup is the standard NNS model. The economy is populated by a large number of identical infinitely-lived households and consists of two sectors: one producing intermediate goods and the other a final good. The intermediate good is produced with capital and labor and the final good with intermediate goods. The final good is homogeneous and can be used for consumption (private and public) and investment purposes.

\subsection{The Household}

Household preferences are characterized by the lifetime utility function 3

$$
E_{t} \sum_{s=0}^{\infty} \beta^{s} U\left(C_{t+s}, 1-h_{t+s}\right)
$$

where $0<\beta<1$ is a constant discount factor, $C_{t}$ and $h_{t}$ respectively denote consumption and hours worked.

In each and every period, the household faces the budget constraint

$$
\begin{aligned}
B_{t}+M_{t}+P_{t}\left(C_{t}+I_{t}+T_{t}\right)+P_{t} \tau\left(v_{t} ; \zeta_{t}\right) C_{t} \leq & P_{t} W_{t} h_{t}+P_{t} z_{t} K_{t}+\Pi_{t}+\ldots \\
& +R_{t-1} B_{t-1}+M_{t-1}+N_{t}
\end{aligned}
$$

where $B_{t}$ and $M_{t}$ are nominal bonds and money acquired during period $t, P_{t}$ is the nominal price of the final good, $R_{t}$ is the nominal interest rate, $W_{t}$ and $z_{t}$ are the real wage rate and real rental rate of capital. The household owns $K_{t}$ units of physical capital, makes an additional investment of $I_{t}$, consumes $C_{t}$ and supplies $h_{t}$ units of labor. It pays lump sum taxes $T_{t}$, receives a transfer of money $N_{t}$ from the government and finally claims the profits, $\Pi_{t}$, earned by the firms. $\tau\left(v_{t} ; \zeta_{t}\right)$ denotes a proportional transaction cost that depends on the household's money-to-nominal consumption ratio, $v_{t}=P_{t} C_{t} / M_{t}$. The

\footnotetext{
$\overline{3 E_{t}(.)}$ denotes mathematical conditional expectations. Expectations are conditional on information available at the beginning of period $t$.
} 
function $\tau(\cdot, \cdot)$ is borrowed from Schmitt-Grohé and Uribe (2004a).

$$
\tau\left(v_{t} ; \zeta_{t}\right)=\zeta_{t}\left(A v_{t}+\frac{B}{v_{t}}-2 \sqrt{A B}\right)
$$

$\zeta_{t}$ is a money demand shock whose properties will be defined later. Letting $\zeta$ tend toward zero 4 we get close to a "cashless" economy.

Capital accumulation is subject to adjustment costs and follows the process

$$
K_{t+1}=I_{t}-\frac{\varphi}{2}\left(\frac{I_{t}}{K_{t}}-\delta\right)^{2} K_{t}+(1-\delta) K_{t}
$$

where $\delta \in[0,1]$ denotes the rate of depreciation and $\varphi \geqslant 0$ is the capital adjustment cost parameter.

The household determines consumption/savings, money holdings and leisure plans by maximizing utility (1) subject to the budget constraint (2) and capital accumulation equation (3).

\subsection{Final Sector}

The representative firm in the final sector produces a homogenous good that may be used for consumption - private or public — and investment purposes. The final good is produced by combining intermediate goods according to a technology described by the following CES function

$$
Y_{t}=\left(\int_{0}^{1} X_{t}(i)^{\theta} \mathrm{d} i\right)^{\frac{1}{\theta}}
$$

where $\theta \in(-\infty, 1)$. $\theta$ determines the elasticity of substitution between the various intermediate goods. The producers in this sector are assumed to behave competitively. Profit maximization yields the following demand functions for $\operatorname{good} i$

$$
X_{t}(i)=\left(\frac{P_{t}(i)}{P_{t}}\right)^{\frac{1}{\theta-1}} Y_{t}
$$

$\overline{4}$ In the practical implementation of the model we set $\zeta=1 \mathrm{e}-12$ 
where the general price index is given by $P_{t}=\left(\int_{0}^{1} P_{t}(i)^{\frac{\theta}{\theta-1}} \mathrm{~d} i\right)^{\frac{\theta-1}{\theta}}$.

\subsection{Intermediate Goods Producers}

Each firm $i, i \in(0,1)$, produces an intermediate good by means of capital and labor according to a constant returns-to-scale technology, represented by the production function

$$
X_{t}(i)=A_{t} K_{t}(i)^{\alpha} h_{t}(i)^{1-\alpha} \text { with } \alpha \in(0,1)
$$

where $K_{t}(i)$ and $h_{t}(i)$ respectively denote the physical capital and the labor input used by firm $i$ in the production process. $A_{t}$ is an exogenous stationary stochastic technology shock, whose properties will be defined later. The firms operate under perfect competition in the input markets but are monopolistically competitive in the product markets. They are assumed to set prices for the good they produce according to the Calvo scheme. In order to maintain long term money neutrality (in the absence of monetary frictions) we also assume that the price set by the non-optimizing firms grows at the steady state rate of inflation, $\bar{\pi}$. This leads to the price setting equation

$$
\widetilde{p}_{t}(i)=\frac{1}{\theta} \frac{E_{t} \sum_{s=0}^{\infty}(1-\gamma)^{s} \pi^{\frac{s}{\theta-1}} \Phi_{t+s} P_{t+s}^{\frac{2-\theta}{1-\theta}} \mathcal{C}_{m, t+s} Y_{t+s}}{E_{t} \sum_{s=0}^{\infty}(1-\gamma)^{s} \pi^{\frac{\theta}{\theta-1}}{ }^{s} \Phi_{t+s} P_{t+s}^{\frac{1}{\theta-1}} Y_{t+s}}
$$

where $\gamma$ is the probability that firm $i$ resets its price in period $t . \Phi_{t}$ is an appropriate discount factor related to the way the household values future as opposed to current consumption and $\mathcal{C}_{m, t}$ is the marginal cost. Then, the aggregate intermediate price index is given by

$$
P_{t}=\left(\sum_{s=0}^{\infty} \gamma(1-\gamma)^{s}\left(\frac{\widetilde{p}_{t-s}}{\bar{\pi}^{s}}\right)^{\frac{\theta}{\theta-1}}\right)^{\frac{\theta-1}{\theta}}
$$




\subsection{The Monetary Authorities}

As mentioned before, our objective is not to characterize the globally optimal policy. But rather to examine whether some simple monetary rules that have been the subject of much debate among academics and central bank economists produce welfare that is very different (and potentially higher) from the constant inflation rule. These popular policy rules may allow for "large" deviations from perfect inflation stability. We study four such rules.

(i) Targeting of the growth rate of the money supply:

$$
\mu_{t}=\bar{\mu}
$$

The nominal interest rate then adjusts to clear the money market.

(ii) Targeting of the nominal interest rate ${ }^{5}$

$$
R_{t}=\bar{R}
$$

In this case, the money supply adjusts in order to clear the money market.

(iii) Perfect inflation targeting. In this case, we consider a rule à la HendersonMcKibbin-Taylor that takes the form

$$
\widehat{R}_{t}=\kappa_{\pi} \widehat{\pi}_{t}
$$

Perfect inflation targeting obtains when $\kappa_{\pi}=\infty 6^{6}$ In this case, as under interest rate targeting, money supply adjusts to clear the money market.

(iv) Imperfect inflation targeting. Under this rule we use a "small" value of $\kappa_{\pi}$ in rule (11). In most of the simulations run involving imperfect inflation targeting we used $\kappa_{\pi}=1.5$.

5 In order to avoid the well known indeterminacy problems, we have specified this rule as follows in the practical implementation

$$
\widehat{R}_{t}=\rho \widehat{R}_{t-1}+(1-\rho) k_{\pi} \widehat{\pi}_{t} \text { with } \rho=0.999 \text { and } k_{\pi}=1.001
$$

where $\pi_{t}$ is the rate of inflation and a ^ stands for log-deviations from the deterministic steady state.

${ }^{6}$ In our experiments, perfect inflation targeting will be approximated by setting $\kappa_{\pi}=10000$. Using greater values for $\kappa_{\pi}$ does not affect our results. 


\subsection{The Government}

The government finances government expenditures on the domestic final good using lump sum taxes. The stationary component of government expenditures is assumed to follow an exogenous stochastic process, whose properties are defined below in section 2 .

\section{Parametrization of the Model}

The model is parameterized on US quarterly data for the period 1960:1-2000:4. The data are taken from the Federal Reserve Database. ${ }^{7}$ The baseline parameters are reported in table 1.

\section{- TABle 1 ABOUt HeRE -}

The nominal growth of the economy is set equal to the sample average of the rate of growth of M1 over the period, implying $\bar{\mu}=2.6 \%$ per quarter. The quarterly depreciation rate, $\delta$, is 0.025 implying an annual depreciation of about $10 \%$. The value of the capital adjustment cost parameter, $\varphi$, is set to 10 in our benchmark experiment. We vary it in our sensitivity analysis from 0 to $\infty$. In the benchmark case, $\theta$ is equal to 0.80 so that the markup rate is $25 \%$ in the steady state. $\alpha$, the elasticity of the production function to physical capital, is set such that the model reproduces the US labor share - defined as the ratio of labor compensation to GDP - over the sample period (0.575). $a_{t}=\log \left(A_{t} / \bar{A}\right)$ is assumed to follow a stationary $\mathrm{AR}(1)$ process of the form

$$
a_{t}=\rho_{a} a_{t-1}+\varepsilon_{a, t}
$$

with $\left|\rho_{a}\right|<1$ and $\varepsilon_{a, t} \leadsto \mathcal{N}\left(0, \sigma_{a}^{2}\right)$. We set $\sigma_{a}=0.0079$ and $\rho_{a}=0.95$.

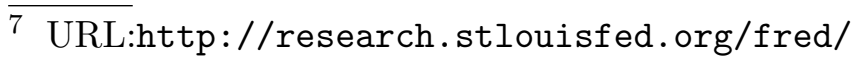


The government spending shock 8 is assumed to follow an $\mathrm{AR}(1)$ process

$$
\log \left(g_{t}\right)=\rho_{g} \log \left(g_{t-1}\right)+\left(1-\rho_{g}\right) \log (\bar{g})+\varepsilon_{g, t}
$$

with $\left|\rho_{g}\right|<1$ and $\varepsilon_{g, t} \sim \mathcal{N}\left(0, \sigma_{g}^{2}\right)$. Estimating this process over the sample period leads to a persistence parameter, $\rho_{g}$, of 0.9696 and a standard deviation of innovations of $\sigma_{g}=0.0098$. The government spending to output ratio is set to its observed sample average, 0.22 .

The instantaneous utility function takes the form

$$
U\left(C_{t}, \ell_{t}\right)=\frac{1}{1-\sigma}\left[\left(C_{t}^{\nu}\left(1-h_{t}\right)^{1-\nu}\right)^{1-\sigma}-1\right]
$$

$\sigma$, the coefficient ruling risk aversion, is set equal to 1.5 in the benchmark case. $\nu$ is set such that the model generates a total fraction of time devoted to market activities of $31 \%$. $\beta$, the discount factor is set such that households discount the future at a $5 \%$ annual rate.

The two parameters, $A$ and $B$, defining the properties of the transaction cost function, are borrowed from Schmitt-Grohé and Uribe (2004a). This led us to set $A=0.0111$ and $B=0.0752$. The money demand shock also follows an $\mathrm{AR}(1)$ process

$$
\log \left(\zeta_{t}\right)=\rho_{\zeta} \log \left(\zeta_{t-1}\right)+\left(1-\rho_{\zeta}\right) \log (\bar{\zeta})+\varepsilon_{\zeta, t}
$$

with $\left|\rho_{\zeta}\right|<1$ and $\varepsilon_{\zeta, t} \sim \mathcal{N}\left(0, \sigma_{\zeta}^{2}\right)$. We use parameter values estimated by Ireland (2004), namely, $\rho_{\zeta}=0.95$ and $\sigma_{\zeta}=0.018$. In the cashless economy the average value of $\zeta$ is set to $1 \mathrm{e}-12,9$. In the non-cashless economy, $\bar{\zeta}$ is set to 1.

$\gamma$, the probability of price resetting is set in the benchmark case at 0.25 , implying that the average length of price contracts is 4 quarters.

$\overline{8}$ The logarithm of the government expenditures are first detrended using a linear trend.

9 Considering smaller values of $\zeta$ does not affect the results. 
In the simulations, we vary capital adjustment costs, $\varphi$, relative risk aversion $\sigma$, the markup $\theta$, the degree of monetary friction, $\zeta$, and the probability of price resetting, $\gamma$.

\section{The Results}

The model is solved using a second order perturbation method (see SchmittGrohé and Uribe (2004b)). An attractive feature of this approach is that it breaks the certainty equivalence property that characterizes the standard loglinear approximation. This allows the volatility terms - which do matter for welfare - to enter the decision rules 10 . The method is therefore more likely to deliver accurate welfare results. The level of welfare is computed taking a high order approximation to the utility function 11 We simulate series for consumption, $\left\{c_{t}\right\}_{t=0}^{T}$, and leisure, $\left\{\ell_{t}\right\}_{t=0}^{T}$, and compute high order moments from the series. These moments are then entered into the approximation of the utility function in order to compute expected welfare. Each series has a length $\mathrm{T}=5000{ }^{12}$ Each experiment is repeated 1000 times and the results are averaged.

In order to produce more meaningful welfare evaluations we have converted expected utility levels into "wealth" equivalent levels 13 according to the following procedure. Let $u^{\star}$ be the level of -maximized-expected, lifetime utility computed under a particular model specification and monetary policy (for instance, in a cashless economy under money supply targeting). Consider the maximization problem: $\max u(c, l) /(1-\beta)$ subject to $\lambda=c+w l$ where $w$ is the steady state wage rate and $\lambda$ will be defined shortly. The solution to this problem is $c=c(\lambda)$ and $l=l(\lambda)$. Plugging the optimal values of $c$ and $l$ into

\footnotetext{
${ }^{10}$ Our solution method takes into account the fact that, unlike the case of a loglinear approximation, there is a non-trivial aggregation problem. Namely, that the "Solow residual" type of term that aggregation introduces into the production function is no longer a constant (see Christiano, Eichenbaum and Evans (2005)).

${ }^{11}$ We report results with a 8 th order approximation. The results do not differ when we considered terms of higher order.

${ }^{12}$ Simulating longer series does not affect our welfare ranking.

${ }^{13}$ We are grateful to Bob King for suggesting this measure.
} 
the utility function gives $u=u(c(\lambda), l(\lambda))=u(\lambda)$. Let $\lambda$ now be determined by equating $u(\lambda)$ to $u^{\star}$. Hence, $\lambda$ is the amount of wealth (permanent income) that is needed under this particular monetary policy in order to support a stationary level of utility equal to $u^{\star}$. We then define the wealth loss (gain), $L$, from pursuing a policy $F$ rather than a policy of perfect inflation $P$ as $L_{F}$ $=100 \times(\lambda(P)-\lambda(F)) / \lambda(P)$.

We are interested in the role played by several important features of the model, namely, the presence of investment, the monetary friction, the degree of risk aversion, the level of capital adjustment costs, the level of average mark ups and the degree of price rigidity (the frequency of price resetting). Capital accumulation is important because, as Goodfriend and King (2001), have argued, the volatility of investment increases the monetary authority's incentive to stabilize employment-consumption by manipulating cyclical markups, which tends to strengthen the case for inflation stability. But at the same time, investment represents an additional channel for intertemporal smoothing for the households that makes it more difficult for the central bank to produce transitory variations in consumption via markup manipulation. Hence, the net effect of the inclusion of capital accumulation cannot be determined on theoretical grounds only.

The monetary friction matters because, in addition to the standard Friedman case for deflation, it makes variation in the nominal interest rate costly. The steady state level of the markup matters because in the absence of a fiscal subsidy, it determines the degree of inefficiency of the equilibrium in the flexible price version of our model and consequently the incentives of the monetary authorities to improve upon it. The degree of price rigidity is important for two reasons. First, it matters for the size of the relative price distortion and hence for the trade off between the various distortions. And second, it determines how much leeway the monetary authorities have on trying to improve upon the inefficient flexible price allocation. The way this is accomplished is via the cyclical manipulation of markups. However, in our setting, manipulating markups over the business cycle involves a tradeoff. On the one hand, the management of markups could in theory reduce the volatility of consumption, employment and/or bring about a more favorable covariance between these 
two variables. On the other hand, letting the markups vary carries a cost because it leaves the relative price distortion in place. One cannot tell a priori how the costs and benefits of imperfect price stabilization vary with the degree of price rigidity. The greater the degree of price rigidity the higher the cost of imperfect price targeting, but at the same time, the greater the ability of the monetary authorities to influence markups. The importance of our results precisely lies in their providing information about the net effect of these two opposing factors.

\section{- TABles 2 AND 3 ABOUt HeRE -}

Tables 2 and 3 report the main results for the cashless $(\zeta=1 \mathrm{e}-12)$ and monetary economy $(\zeta=1)$ respectively. The tables contain results from a large number of specifications and experiments and aim at conveying information about the type of policy that fares best relative to the perfect inflation targeting rule (and how well quantitatively) as a function of a vector of the main features of the model, and information about the macroeconomic properties of these policies (volatility of inflation and output). The tables are designed on the following principles: First, that the two most important features explored in the analysis are the role played by capital and the effect of risk aversion. Hence the top half in each table reports results from the benchmark economy without capital and the bottom half from the economy with capital accumulation. The left half reports results with standard risk aversion $(\sigma=1.5)$ while the right one with high risk aversion $(\sigma=3.5)$. Second, it takes into account the fact that the perfect inflation targeting rule is the benchmark, so that all other rules are to be compared to it in terms of the loss measure described above. Third, the tables show the result of a specification -across policy rules- search for the "best" rule, that is the rule that produces the largest gain (smallest loss) over the inflation targeting rule for each of the important model features discussed above (the degree of price rigidity, capital adjustment costs and the mark up). In addition and for completeness purposes, we report the results for the general parametrization described in Table 1. Fourth, the tables also report the volatility of output and inflation for the "best" rule and the inflation targeting rule. All this information is reported for each one of the three shocks in the model (supply, A, fiscal, G, and monetary, M). 
As an illustration, consider the third cell in the first row in Table 2. It says that as far as variation in the markup $(\theta)$ is concerned and in the face of supply shocks, the rule that performs the best against the perfect inflation targeting rule is monetary targeting $(M T)$. This obtains when the steady state mark up is quite large $(\theta=0.7$, that is, a markup of $43 \%)$. The associated relative loss is $0.0044 \%$. That is, the agents would be willing to give up 0.0044 of their wealth in order to prevent a switch from a perfect inflation targeting rule to the second best (among the 5 rules considered) monetary targeting one. We can also see that this second best rule entails slightly less output volatility than the perfect inflation targeting rule (a standard deviation of 1.98 vs 2.17) but significantly more inflation volatility ( 0.41 vs 0$)$.

The main pattern that emerges in the "cashless" version of the model is that none of the four rules described in section 1.4 does better than perfect inflation targeting. Only when investment is present and prices are flexible 14 the imperfect inflation targeting rule does better than perfect targeting rule (under both supply and fiscal shocks). But in this case the welfare advantage is completely negligible (less than $0.12 \mathrm{e}-08$ ).

These findings are interesting because one might have thought that the parameters determining the strength of the distortions would have played a major role for the welfare rankings of the monetary policies considered. In particular, one may have presumed that the greater the inefficiency of the flexible price economy (the lower the $\theta$ ), the weaker the incentive to replicate the flexible price equilibrium would have been. Similarly, one may have thought that price stability would lose its appeal if the relative price distortion were small. Apparently, our results suggest that, as prices become more flexible, the ability to manipulate markups decreases faster than the cost of the relative price distortion.

The results are similar in the version of the model that also allows for a "non-negligible" monetary distortion $(\zeta=1)$. Perfect inflation stabilization is outperformed by other rules as long as the degree of price flexibility is quite

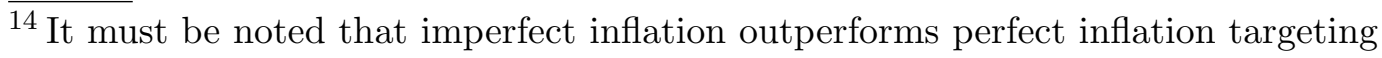
in this case even with some small price rigidity $(q \geqslant 0.75)$.
} 
high 15 . In this case, low risk aversion works in favor of those other rules. Or if risk aversion is high, investment is also needed to be present for these rules to perform better. One can thus claim that capital accumulation and a monetary friction can undermine the case for perfect price stability for all types of shocks and independent of the level of risk aversion and mark ups as long as prices are quite (but not necessarily perfectly) flexible. Moreover, the degree of price instability tolerated by these rules is non negligible.

But before proceeding to argue, based on the findings reported above, that inflation targeting is a bad idea one must first consider the following caveat. It should not be forgotten that the practical relevance of policy induced fluctuations in the inflation rate is limited when prices are relatively flexible (unless the monetary distortion is quantitatively very large, which seems rather unlikely). This is due to the fact that, in this case, money does not matter much for real economic activity and hence the welfare differences across different policy rules range from quite small to negligible. For instance, the gains from following an imperfect rather than a perfect inflation targeting rule when prices are slightly rigid $(q=0.75)$ tend to be smaller than $0.1 \mathrm{e}-08$ of permanent income. Consequently, our view is that one should not see the results as significantly weakening the case for perfect price stability in the NNS model.

What is the explanation for these findings? We think that the reason that both distortions as well as investment are needed in order for some inflation variability to be desirable is related to the behavior of the gap between the natural rate and the efficient equilibrium. This wedge is constant with the monopolistic distortion but variable with the monetary friction. Nevertheless, as the time variation in this wedge is quite limited due to the small role played by real balances for economic activity in models such as hours, the deviation from perfect price stability is not quantitatively significant even in the presence of investment (as conjectured by Goodfriend and King (2001) and Woodford (2003)).

\footnotetext{
${ }^{15}$ While these other rules do best against the perfect inflation rule when prices are perfectly flexible, they still do better as long as price rigidity is limited. In particular, these rules start doing better at around $q=0.75$, that is with a quarterly frequency of price adjustment.
} 


\subsection{The Kim and Kim Critique}

In an recent paper, Kim and Kim (2003) have demonstrated that using a first order log-linear approximation to the decisions rules and a second order approximation to the utility function (a popular practice) can lead to erroneous welfare computations (see also Woodford (2003), for a general discussion of this issue). In order to gauge the relevance of the Kim \& Kim critique for our model we have solved the model and computed welfare using the following alternative procedures: (a) log-quadratic approximation to both the decision rules and to utility (QQ in the table), (b) log-linear approximation to the decision rules and high order approximation to utility (L8 in the table) and (c) log-linear approximation to the decision rules and quadratic approximation to utility (LQ in the table). Recall that the results reported above are obtained using a log-quadratic approximation to the decision rules and a high order approximation to utility (Q8 in the table). Table 4 offers a comparison.

\section{- TABle 4 ABOUT HeRE -}

Two features stand out. First, procedure (a) above and our procedure lead to identical results. Hence, a second order approximation to utility is sufficient when the decision rules are approximated at the second order. And second, the Kim \& Kim critique does apply to a model such as ours. Thus it is indeed the case that procedures (b) and (c) above may produce misleading welfare comparisons of alternative policies. For instance, based on a log-linear approximation to the decisions rules one would conclude that money targeting does better than perfect inflation targeting in the case of supply shocks, while the results from the second order approximation suggest exactly the opposite.

\section{Concluding Remarks}

The New Neoclassical Synthesis literature has presented a very strong case for inflation stabilization. Nevertheless, the general applicability of this result has remained unknown because of some restrictive features of the models that have been used to analyze optimal monetary policy (for instance, the absence of 
investment). The valued added of this paper can be found in its use of a more general specification to address the issue of price stability. Our results confirm Goodfriend and King (2001) conjecture that the case for inflation stabilization may not be undermined by the inclusion of capital accumulation.

We have shown that this conjecture is valid independently of many key features of the model (risk aversion, size of mark up, level of capital adjustment costs) as long as prices are not very flexible. But when prices are very flexible, monetary policy does not matter much and hence the issue of optimal monetary policy is of little practical relevance. A possible explanation for the maintained strength of the case for inflation stability is that our model exhibits limited variation in the gap between the natural and the efficient level of output. In particular, the monopolistic distortion induces a constant wedge between these two quantities while the monetary friction's influence on that wedge is weak. It remains to be seen whether the case for inflation stability will retain its validity in models with capital accumulation and other distortions, if those distortions induce significant variation in the the gap between the natural and the efficient level of output.

\section{References}

Christiano, L.J., M. Eichenbaum, and C. Evans, Nominal Rigidities and the Dynamic Effects of a Shock to Monetary Policy, Journal of Political Economy, 2005, 113, 1-46.

Clarida, R., J. Galí, and M. Gertler, The Science of Monetary Policy: A New Keynesian Perspective, Journal of Economic Literature, 1999, 37, 1661-1707.

Goodfriend, M. and R.G. King, The New Neoclassical Synthesis and the Role of Monetary Policy, in B. Bernanke and J. Rotemberg, editors, NBER Macroeconomics Annual, Cambridge (MA): MIT Press, 1997.

__ and _ _ The Case for Price Stability, Working Paper 8423, NBER 2001.

Henderson, D. and W. McKibbin, A Comparison of Some Basic Monetary Policy Regimes for Open Economies: Implications of Different Degrees of Instrument Adjustment and Wage Persistence, Carnegie Rochester Conference Series on Public Policy, 1993, 39, 221-317.

Ireland, P., Money's Role in the Monetary Business Cycle, Journal of Money, Credit, and Banking, 2004, 36, 969-984. 
Khan, A., R.G. King, and A. Wolman, Optimal Monetary Policy, Review of Economic Studies, 2003, 70, 825-860.

Kim, J. and S.H. Kim, Spurious welfare reversals in international business cycle models, Journal of International Economics, 2003, 60, 471-500.

Schmitt-Grohé, S. and M. Uribe, Optimal Fiscal and Monetary Policy Under Sticky Prices, Journal of Economic Theory, 2004, 114, 198-230.

__ and __ Solving Dynamic General Equilibrium Models Using a SecondOrder Approximation to the Policy Function, Journal of Economic Dynamics and Control, 2004, 28, 755-775 .

Woodford, M., Interest and Prices, Princeton: Princeton University Press, 2003. 
Table 1

Calibration: Benchmark case

\begin{tabular}{lrr}
\hline \hline \multicolumn{1}{c}{ Technology } & & \\
\hline Capital elasticity of intermediate output & $\alpha$ & 0.2500 \\
Capital adjustment costs parameter & $\varphi$ & 10.0000 \\
Depreciation rate & $\delta$ & 0.0250 \\
Parameter of markup & $\theta$ & 0.8000 \\
Probability of price resetting & $q$ & 0.2500 \\
\hline \multicolumn{1}{c}{ Preferences } & & \\
\hline Discount factor & $\beta$ & 0.9880 \\
Relative risk aversion & $\sigma$ & 1.5000 \\
CES weight in utility function & $\nu$ & 0.3405 \\
Money demand parameter & $\zeta$ & 1.0000 \\
Parameter of transaction cost (linear) & $\mathrm{A}$ & 0.0111 \\
Parameter of transaction cost (constant) & $\mathrm{B}$ & 0.0752 \\
\hline \multicolumn{3}{c}{ Shocks } \\
Persistence of technology shock & $\rho_{a}$ & 0.9500 \\
Standard deviation of technology shock & $\sigma_{a}$ & 0.0079 \\
Persistence of government spending shock & $\rho_{g}$ & 0.9696 \\
Volatility of government spending shock & $\sigma_{g}$ & 0.0098 \\
Persistence of money demand shock & $\rho_{\zeta}$ & 0.9500 \\
Volatility of money demand shock & $\sigma_{\zeta}$ & 0.0180 \\
\hline \hline
\end{tabular}




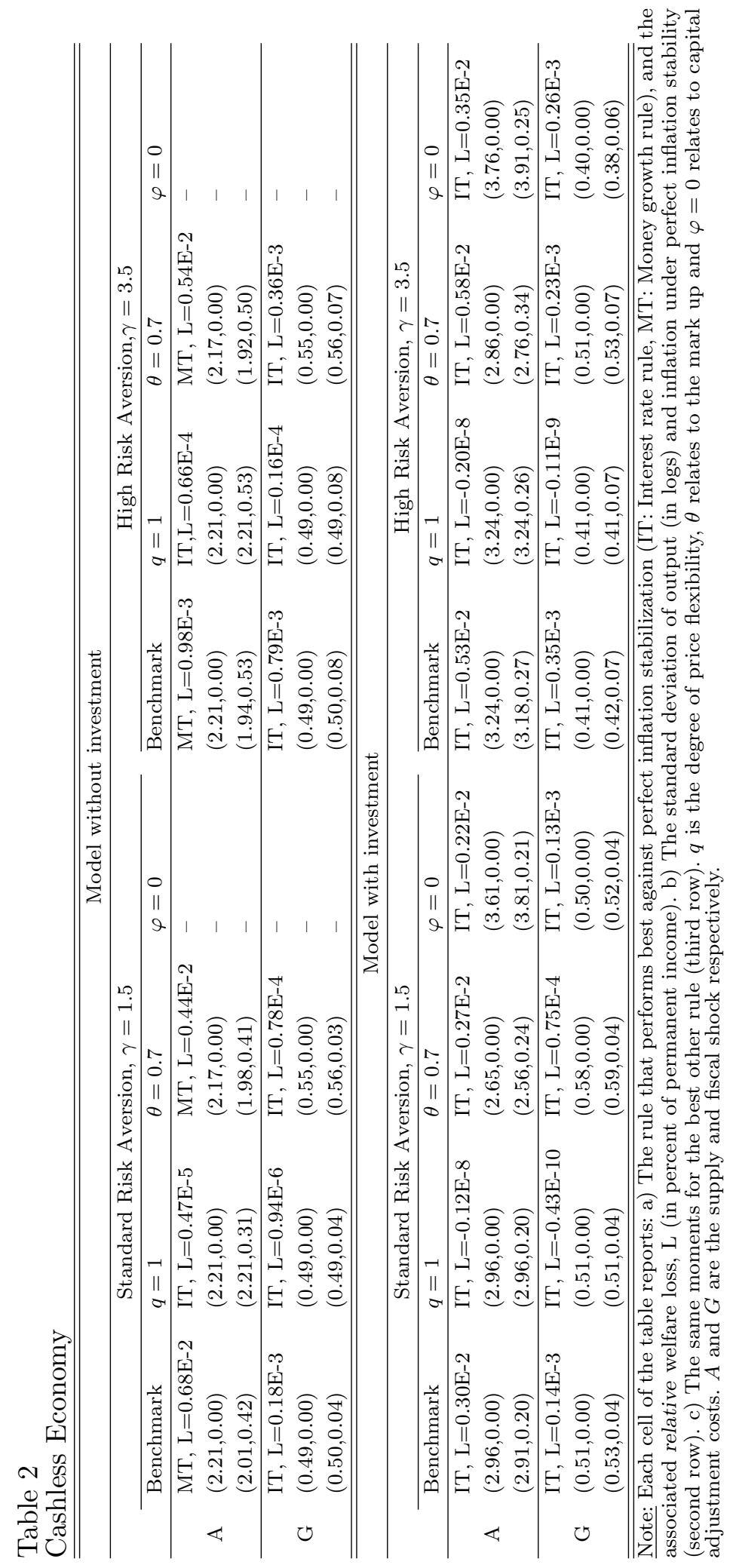




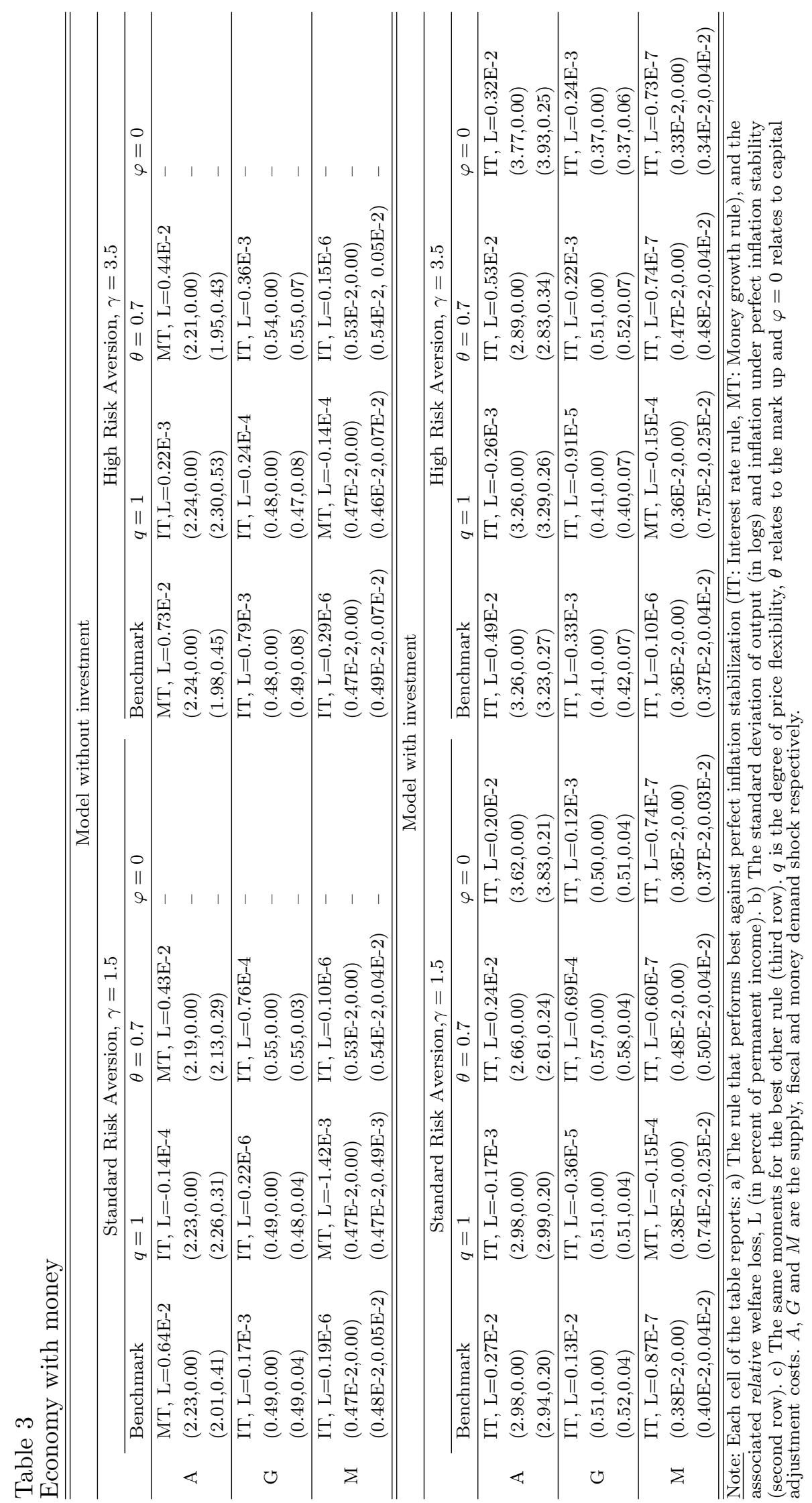




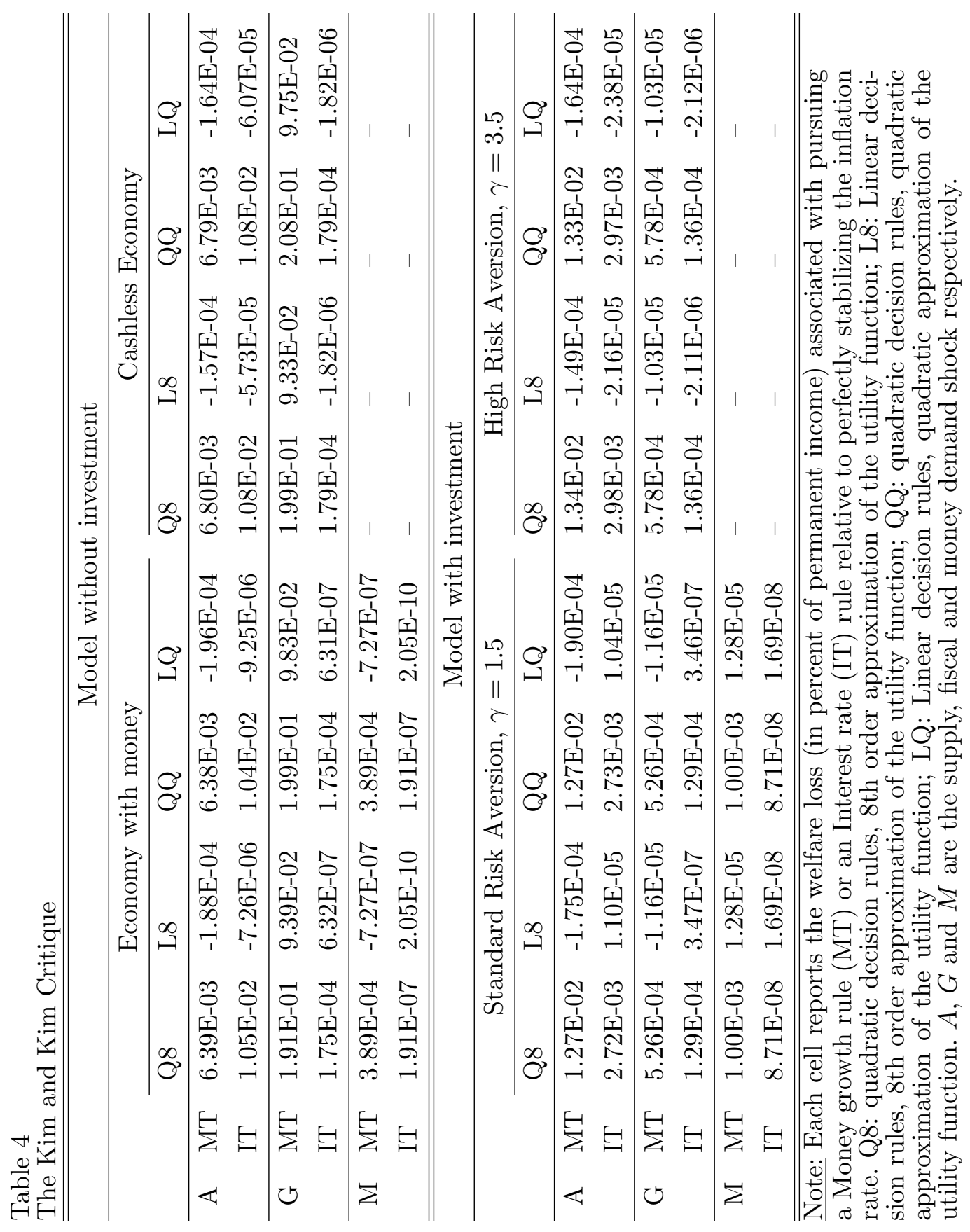

